Fecha de recepción: diciembre 2018 Fecha de aceptación: marzo 2019 Versión final: junio 2019

\section{El Movimiento de Mujeres Indígenas por el Buen Vivir. Intersticios de una lucha feminista, antiextractivista y por la Plurinacionalidad}

Marina Mendoza *

Resumen: El Movimiento de Mujeres Indígenas por el Buen Vivir condensa la complejidad del escenario latinoamericano actual, signado por la emergencia de formas de resistencia y expresiones de alteridad que se reconfiguran al calor de las transformaciones políticas y económicas de la región. Este artículo se propone analizar las estrategias de visibilización y comunicación desarrolladas por el Movimiento desde su primera aparición pública, indagando el modo en que, desde un espacio alternativo, expresan la reivindicación de la Plurinacionalidad, la construcción de liderazgos femeninos y la relación con los Estados locales y nacionales frente al avance del neoextractivismo.

Palabras clave: Comunidades indígenas - antiextractivismo - feminismo - criminalización - territorios ancestrales - Plurinacionalidad - genocidio originario - comunicados oficiales - redes sociales - visibilización.

[Resúmenes en inglés y portugués en las páginas 127 - 129]

(*) Becaria Doctoral del CONICET, Doctoranda en Ciencias Sociales (FSOC-UBA), Licenciada en Sociología (FSOC-UBA) y Licenciada en Relaciones Públicas (UP). Ha cursado estudios de posgrado en Derechos Humanos y Genocidios (Fundación Luisa Hairabedian/UMSA), Memoria colectiva y prácticas de resistencia (CLACSO), Integración regional y regionalismo en Europa y América Latina (Escuela Complutense Latinoamericana), Geopolítica y Defensa Latinoamericana (CCC Floreal Gorrini) y Comunicación Política (Centro de Comunicación La Crujía). Es profesora de Seminario de Integración I (Universidad de Palermo) y Ayudante de Primera de la cátedra Sociología Política de América Latina (UBA). Forma parte del Ubacyt "Estado, élites y grupos económicos en América Latina”, dirigido por la Dra. Inés Nercesian.

\title{
Introducción
}

El 30 de junio de 2018, el Movimiento de Mujeres Indígenas por el Buen Vivir (MMIBV) realizó su primera aparición pública en el escenario político argentino. Con la Marcha de Mujeres Originarias como antecedente (creada en 2012), la organización plurinacional 
manifestó la necesidad de visibilizar una compleja red de luchas enraizadas en su triple exclusión: étnica, de género y de clase.

Paulatinamente, y al calor de la exacerbación de los conflictos entre los Estados nacionales y las comunidades indígenas, el movimiento adquirió un carácter antiextractivista, impulsando el Buen Vivir como un modelo de desarrollo alternativo.

La criminalización de la protesta social -y territorial particularmente-, que en Argentina se radicalizó durante el mandato del presidente Mauricio Macri (2015-), así como el procesamiento judicial de líderes mapuches en una estrategia que excede los límites nacionales, exigió un viraje en el esquema comunicacional inicial del Movimiento.

En este artículo se propone analizar el MMIBV a partir de sus materiales de difusión -comunicados, videos, panfletos e invitaciones a jornadas-, en un periodo temporal que abarca desde su surgimiento a mediados de 2018 hasta marzo de 2019. La estrategia de comunicación y visibilización del Movimiento es íntegramente digital, utilizando la plataforma de Facebook como eje principal de su vínculo con la ciudadanía.

Su exclusión de facto de los medios de comunicación hegemónicos y la escasa o nula percepción pública del problema que atraviesan estas comunidades -ante el sistemático silenciamiento de los funcionarios públicos locales y nacionales-, conllevó a la utilización de mecanismos alternativos de debate y denuncia. Este elemento resulta de particular interés, en tanto no se trata simplemente de una elección, sino que refleja la capacidad de ser reconocidas en la esfera pública a través de esta única vía masiva. Asimismo, el propio carácter de esta plataforma permea el contenido de las piezas, su capacidad de replicación, las modalidades de difusión y las estrategias discursivas.

Es por ello que el presente artículo propone describir y analizar los comunicados oficiales, panfletos y materiales de difusión del MMIBV, a partir de tres ejes de indagación: el rol de la mujer como líder; la reivindicación de la Plurinacionalidad; y el vínculo con los Estados -local y nacional-, en el que se vislumbra, asimismo, la tensión entre un modelo de desarrollo primario-exportador neoextractivista y un modelo alternativo centrado en la filosofía del Buen Vivir.

\section{El contexto de emergencia del Movimiento}

El surgimiento de diversas formas de resistencia al modelo económico neoextractivista en América Latina durante los últimos quince años ha conducido a la necesidad de reponer la pregunta de cuál es el vínculo entre los Estados y las comunidades históricamente excluidas, entre las que destacan los pueblos indígenas.

El concepto de neoextractivismo es empleado para caracterizar la nueva fase de acumulación iniciada circa 2003 en América Latina y que consiste en la consolidación regional de un modelo de desarrollo primario-exportador y el consecuente abandono de una vía industrialista. Esto significó el retorno a un modelo que fue hegemónico a partir de la inserción de la región en la división internacional del trabajo como proveedora de materias primas desde las colonias hacia Europa (proceso que Marx en 1867 denominaría de acumulación originaria del capital) y continuó en la era republicana, hasta que comenzó a 
ser cuestionado tras la Segunda Guerra Mundial en el marco de desarrollo del modelo de industrialización por sustitución de importaciones (ISI), relativamente exitoso en Argentina, Brasil y México (Lander, 2014).

La incidencia de las dictaduras institucionales de las Fuerzas Armadas de los años 1970, la crisis de la deuda de 1980 y la implementación de las políticas neoliberales enfocadas en reorientar la estrategia de desarrollo -de un modelo estado-intervencionista con promoción del mercado interno, hacia una estrategia de desarrollo hacia afuera, con el sector privado como actor protagónico-, condujeron al abandono del modelo de industrialización. Las políticas de ajuste, la reforma tributaria, la apertura comercial, la liberalización financiera, la privatización de empresas estatales, la reforma jubilatoria y la reforma laboral, contribuyeron en su conjunto a una reestructuración del modelo de desarrollo productivo (Ramos, 1997), "reimponiendo la teoría de las ventajas comparativas y la idea de que América Latina necesita concentrarse en producir commodities" (Lander, 2014). Las principales diferencias entre estas nuevas formas de extractivismo y las modalidades clásicas, se basan en la expansión de las fronteras de explotación, la exportación de bienes primarios a gran escala, la injerencia de capitales transnacionales, la financiarización de los bienes de la naturaleza y la ocupación intensiva del territorio, sin generación significativa de puestos de trabajo (Svampa, 2013).

Una de las diferencias más destacadas es el mayor control estatal de las rentas provenientes de estas actividades y su utilización para el financiamiento de programas sociales, como las Políticas de Transferencia Monetaria Condicionadas orientadas a limitar la reproducción intergeneracional de la pobreza a través de mejoras en salud, educación y jubilaciones. Asimismo, un dato novedoso de esta nueva fase es el ingreso de China como uno de los principales demandantes de los insumos generados en la región, desplazando en algunos casos a los mercados norteamericano y europeo.

En toda la región, las exportaciones crecieron ininterrumpidamente entre 2003 y 2008 alcanzando márgenes históricos de incremento del PBI, concentrándose en minería, energía y materias primas agrícolas. La crisis capitalista mundial de 2008 generó un retroceso en la demanda de estos bienes, si bien ya para 2009 muchos mercados habían recuperado su posición previa.

Más allá del carácter marcadamente neoliberal o posneoliberal de los gobiernos latinoamericanos, interesa señalar que el escenario regional expresa "no sólo un acoplamiento entre extractivismo y neoliberalismo, expresado de manera emblemática por Perú, Colombia y México, sino también entre extractivismo y gobiernos progresistas, como sucede en Bolivia, Brasil, Ecuador y Argentina" (Svampa, 2013, p. 371). Esto condujo a autores como Svampa a nominar esta fase como "consenso de los commodities", caracterizado por el "pasaje del consenso de Washington" a un nuevo modo de dependencia o consenso de Beijing (por el protagonismo de China en la demanda de materias primas de los países latinoamericanos). Esta fase requiere la intervención del Estado, que "emerge como palanca de esta lógica de acumulación extractivista” (Acosta, 2012, p. 19).

Allí donde las expresiones de protesta o resistencia amenazan parcial o totalmente la continuidad de esta fase de acumulación, los Estados aparecen respondiendo de manera preventiva, mediante la instauración de estados de excepción; o represiva, mediante la 
criminalización de las comunidades en conflicto, la militarización de las áreas en disputa o el procesamiento judicial de los defensores y activistas, por una variedad de calificativos, que incluyen desde delitos comunes hasta el crimen de terrorismo.

La lucha por la tierra se encuentra en el centro de reivindicación de estas comunidades y, si bien la intensificación de las actividades extractivas desde 2002 hacia áreas no convencionales ha introducido nuevas formas de exclusión, es preciso comprender la criminalización contemporánea en un continuum histórico.

Desde la conquista de América en 1492, las comunidades indígenas comenzaron a sufrir un doble proceso de colonización de sus tierras por medios violentos y su introducción en formas de trabajo forzado para garantizar la extracción de metales y materias primas que durante el Siglo XVI fueron esenciales para crear el mercado mundial.

Particularmente, las comunidades mapuches eran agricultoras y se encontraban establecidas en los márgenes de los ríos Itata y Toltén (actual territorio chileno), donde habían construido una sociedad de un millón de personas en torno a actividades agrícolas y pesqueras. Si bien no contaban con una estructura estatal, cada "caserío" tenía su propia autoridad (Bengoa, 2007). No había, en la organización social mapuche una división del trabajo, más allá de "responsabilidades individuales de los miembros de una familia extendida y compleja (Pizarro, 2011). Los mapuches presentaron una fuerte resistencia a la dominación española durante el período colonial, hasta que fueron derrotados y sus territorios anexados a los estados nacionales de Chile (1883, fin del proceso de "Pacificación de la Araucanía") y Argentina (1885, fin de la "Campaña del Desierto").

Los nuevos Estados necesitaban construir una identidad nacional homogénea que subsumiera otras nacionalidades a una gran nación. En este proceso, las nacionalidades indígenas quedaron parcialmente incluidas o totalmente excluidas, en la mayoría de los casos. Durante este período, la discusión se centraba en considerarlos ciudadanos o no, lo que con frecuencia se soslayaba frente a la incerteza respecto de su estatus de persona. Detrás de estas discusiones se escondía el interés de las élites ibéricas y americanas de mantener el control sobre estas comunidades.

Otro de los pilares del modelo de Estado-nación, además de la identidad, es el territorio. Durante el Siglo XIX, tanto el Estado chileno como el argentino decidieron incorporar las tierras de estas comunidades a la nueva organización política: cinco millones de hectáreas en el caso chileno y más de cuarenta millones en el caso argentino, habitadas no sólo por mapuches, sino también por comunidades pampa, ranquel y tehuelche (Prado, 1966).

En el Siglo XX, algunas de las tierras fueron subastadas por el Estado y comenzaron a ser explotadas por colonos extranjeros. En el marco de las discusiones por estos territorios, emerge la "cuestión mapuche", es decir, se reconoce que existe un conflicto entre los Estados y las comunidades que los preexistían. En Chile, durante el régimen militar pinochetista (1973-1990), la aprobación de una ley de 1978 dividió la propiedad comunal para "crear un mercado de tierras y resolver el conflicto indígena" (Bengoa, 2000).

Ambos países aprobaron durante la década de 1990 el Convenio 169 de la Organización Internacional del Trabajo, que reconoció las aspiraciones de las comunidades indígenas de tomar el control de sus propias instituciones, modos de vida y desarrollo económico, entre otros elementos. Este proceso se dio en un contexto de creciente consolidación del 
paradigma de diversidad cultural, que con frecuencia se tradujo en el reconocimiento oficial de etnias y grupos que habían sido invisibilizados.

Sin embargo, desde los primeros años del Siglo XXI, el "consenso de los commodities" (Svampa, 2013), contribuyó a la profundización de la colonización estatal y transnacional de las tierras indígenas. Las comunidades mapuches, tanto dentro de los límites chilenos como argentinos, son criminalizadas por la reivindicación de su autonomía y la denuncia de la represión de la que son víctimas por proteger sus tierras ante el intento de adquisición por parte de capitales transnacionales mineros, forestales o hidrocarburíferos.

La necesidad de emplear esos territorios para las actividades extractivas condujo a diferentes prácticas de criminalización. En Argentina, ha habido ingentes esfuerzos por mostrar la "cuestión mapuche" como un problema foráneo, uno que Chile debe resolver. De aquí que muchos de los líderes procesados han sido extraditados al país vecino, donde rige un marco legal que emplea, casi con exclusividad, el delito de terrorismo para judicializar las manifestaciones de defensa de la tierra por parte de comunidades mapuches.

Otra estrategia empleada por las élites políticas de ambos países -y reproducida en las corporaciones mediáticas afines- es vincular sus prácticas de resistencia con redes internacionales de terrorismo u organizaciones como las Fuerzas Armadas Revolucionarias de Colombia (FARC) o Euskadi Ta Askatasuna (E.T.A.) que proclamaba la independencia de la nación vasca y la creación de un Estado socialista (Lenton, Delrio, Pérez, Papazian, Nagy y Musante, 2011).

En Argentina, desde el Ministerio de Seguridad se sostiene que los actos de reivindicación son perpetrados por una guerrilla rural denominada Resistencia Ancestral Mapuche (RAM), orientada a crear un Estado separado y dispuesta a usar medios violentos para lograrlo . Esta estrategia "crea un terrorismo interno", al quitarle la historicidad a las demandas de estas comunidades (Papazian, 2017). Para Lenton (2018) esto es parte de un proceso de negación o deslegitimación de "la militancia indígena en espacios de "la política", con el agravante de que "el discurso hegemónico persiste aún hoy en leer las manifestaciones originarias en clave de peligrosidad”, introduciéndose esta novedad del vínculo terrorista (p. 60).

Es importante señalar que las prácticas de criminalización y represión en las que muchos defensores mapuches han resultado asesinados por fuerzas policiales, Prefectura Naval o Gendarmería, así como el discurso de tratarse de un problema externo, tuvo un momento de radicalización en el marco de la discusión sobre la extensión de la Ley N²6160 (Papazian, 2017). Esta ley suspendía los desalojos hasta que el Estado cumpliese con la realización de análisis territoriales que permitieran a las comunidades defender sus derechos sobre la tierra. Uno de los principales motivos por los cuales estas prácticas pueden desplegarse con cierto nivel de aceptación pública, es porque las élites gubernamentales suelen contar con el apoyo de los medios de comunicación hegemónicos -elemento que será retomado en sucesivos apartados, ya que el MMIBV emplea medios alternativos para lograr visibilizar sus demandas-.

El proceso de criminalización no tiene sólo consecuencias a un nivel legal: incluso cuando algunos de los líderes indígenas o defensores ambientales son encarcelados, con frecuencia son liberados y las causas cerradas. El principal propósito es desmovilizarlos y restar visibilidad a sus demandas, en una estrategia que responde a diversas causas. 
La primera es que se asientan sobre los territorios donde se hallan los recursos naturales que los Estados nacionales requieren para garantizar la extracción de estos bienes. Actualmente, en Argentina se encuentran en desarrollo proyectos de megaminería en Chubut, provincia donde la minería a cielo abierto está prohibida desde el año 2003, por Ley $\mathrm{N}^{\circ} 5001$, lograda por la oposición de la población y que sirvió de modelo para que otras siete provincias detuvieran las actividades mineras en sus territorios. En la misma provincia, la Hidroeléctrica La Elena propone el uso de la cuenca del Río Carrenleufú -también denominado Río Corcovado- para la creación de una central hidroeléctrica que alimente la planta industrial de la fábrica de aluminio Aluar en Puerto Madryn y se proyecta sobre áreas aledañas a la comunidad Pillán Mahuiza, de la cual es referente la weichafe Moira Millán, una de las ideólogas del MMIBV.

Finalmente, cabe mencionar los proyectos de extracción de hidrocarburos por fracturación hidráulica (fracking) en el yacimiento Vaca Muerta -ubicado mayoritariamente en la provincia de Neuquén, parte de Río Negro y parte de Mendoza- que generan desde 2013 -cuando se firmaron acuerdos de explotación entre la estatal argentina Yacimientos Petrolíferos Fiscales y la estadounidense Chevron- conflictos entre los Estados locales y dos grupos que se oponen a estas actividades: las Asambleas del Agua y las comunidades mapuches.

La segunda causa responde a que estas comunidades -así como muchas otras poblaciones originarias de la región-, expresan un tipo de organización social diferente al Estado-nación. La tercera causa es que sus propias actividades microeconómicas demuestran que es posible gestar un modelo de desarrollo económico alternativo, en respeto con la naturaleza. Y en último lugar, se busca su invisibilización porque expresan más de medio siglo de exclusiones. En Argentina, la instauración de actividades extractivas no es un fenómeno reciente. La consolidación del modelo del agronegocio, es un fenómeno que puede situarse en la década de 1970, con el inicio de las políticas de extranjerización y liberalización de la economía que estimuló el gobierno dictatorial. Sin embargo, la expansión de la frontera extractiva a zonas otrora consideradas improductivas o protegidas por reivindicaciones ancestrales, así como la explotación de minería que se incrementó casi en un 300\% entre 2003 y 2008 (Lander, 2014) en un país como Argentina que no tiene una fuerte tradición histórica en este sector, dieron inicio a un nuevo ciclo de conflictividad. Esta explosión de formas de protesta significó la simbiosis entre las luchas ancestrales por la tierra de las comunidades originarias y las asambleas ciudadanas.

La demanda sostenida de productos agrícolas durante buena parte del boom de los precios internacionales de los commodities, respondió a la demanda china. Sin embargo, la transición del gigante asiático de la industria a los servicios comenzó a reducir la demanda de estas materias primas. Este proceso coincidió con el arribo a la presidencia del empresario Mauricio Macri (2015), más inclinado a los intereses norteamericanos y abiertamente librecambista. Esto condujo al pasaje de una política de hidrocarburos intervencionista, desarrollada durante los gobiernos de Néstor Kirchner (2003-2007) y Cristina Fernández (2007-2015) a una política de mercado abierto (Scandizzo y Mullally, 2018), que liberalizó el abastecimiento de energía. Se gestó así un compromiso renovado con la megaminería a gran escala en la Patagonia. 
Respecto al carácter feminista de la lucha, el Movimiento emerge en un contexto de crecimiento de la demanda por igualdad de género y la superación de una sociedad patriarcal, machista y heteronormativa que históricamente ha relegado a la mujer a una situación de inferioridad, gestando una multiplicidad de formas de violencia. Estas prácticas incluyen desde la naturalización de la existencia de "techos de cristal", hasta el acoso callejero, la violencia otrora considerada doméstica, la violencia verbal y el feminicidio . En el caso del colectivo indígena, estas situaciones de violencia se potencian por lo que sus interlocutoras denominan la hegemonía de una cultura "colonial, patriarcal, machista y capitalista" que reproduce modos de exclusión históricos.

Si bien en aquellos casos que, a nivel regional, se ha institucionalizado el Buen Vivir a nivel constitucional, como Ecuador (2008) y Bolivia (2009), se afirma que "no es posible el Buen Vivir sin la igualdad de género", esta concepción desde el Estado no necesariamente traduce lo que algunas comunidades planten como feminismos comunitarios y decoloniales. En efecto, pareciera que la búsqueda de diversidad propia de algunos procesos latinoamericanos se ha centrado principalmente en torno a manifestaciones culturales, pero las jerarquías de género y sexualidad "se limita[n] y se ordena[n] de acuerdo a parámetros definidos por una heteronormatividad uninacional" (Varea y Zaragocin, 2017, pp. 6-7).

En cambio, el feminismo decolonial es una propuesta híbrida entre los aportes del "feminismo negro, de color y tercermundista" que, desde una lectura que se reivindica en este artículo, ha planteado la inseparabilidad de la opresión de clase, raza, género y sexualidad; y, por el otro, "recupera el legado de las mujeres y feministas afro descendientes e indígenas que (...) han planteado el problema de su invisibilidad dentro de los movimientos sociales y dentro del propio feminismo" (Espinosa, 2014, p. 32).

Como se observará en el análisis de los comunicados del MMIBV, las tensiones entre un feminismo "occidental" y un feminismo decolonial, expresan la existencia de diversas concepciones de un mismo fenómeno, frente a la tendencia a la homogeneización. Este mismo proceso es el que subyace detrás de la apropiación de conceptos propios del Buen Vivir por parte de los Estados plurinacionales, como Bolivia y Ecuador, que tienden a esencializar a las comunidades indígenas -y por tanto, a homogeneizar sus prácticas-. En estas lecturas ahistóricas, cualquier ruptura con la lectura hegemónica es vista como una amenaza a la supervivencia del grupo (Hernández Castillo, 2017).

\section{Los orígenes del Movimiento}

La presentación pública del Movimiento de Mujeres Indígenas por el Buen Vivir se realizó el sábado 30 de junio de 2018 en un acto que tuvo lugar en la sede de la fábrica recuperada de Industrias Metalúrgicas y Plásticas Argentina (IMPA), en el barrio porteño de Almagro. La conversión de la Marcha de Mujeres Originarias por el Buen Vivir en Movimiento significó el inicio de un proceso de transformación tendiente a lograr "el fortalecimiento de la lucha de los 36 pueblos y naciones indígenas que habitan este territorio, para que se respeten sus derechos contra el constante avasallamiento de los mismos por parte de las clases dominantes y los gobiernos de turno" (Polischuk, 2018). 
La Marcha de Mujeres Originarias por el Buen Vivir tuvo su fecha fundacional en el año 2012 en un centro cultural de la comunidad Qom ubicado en un barrio de Rosario (Santa $\mathrm{Fe}$, Argentina). En esa oportunidad, un grupo de mujeres de diversas nacionalidades gestó la propuesta de impulsar una marcha masiva hacia el Congreso de la Nación para hacer visibles no sólo su existencia, sino también la posibilidad fáctica de promover el Buen Vivir como un modelo de desarrollo posible. Esa propuesta tomó forma tres años después en la localidad de Epuyén, cuando se generó un anteproyecto de ley que fue presentado en el Congreso nacional como corolario de la primera marcha que realizaron. A ésta le siguió otra marcha en 2016, donde presentaron un petitorio que, al igual, que el anteproyecto de ley, tampoco obtuvo respuesta gubernamental.

Frente al silencio de parte de los funcionarios, decidieron virar su estrategia de acción y colocar el foco del Movimiento en el desarrollo de métodos de concientización y denuncia. La invisibilización que sufren las comunidades indígenas desde las esferas gubernamentales es una de las formas de negacionismo que los distintos gobiernos han adoptado respecto al genocidio sobre el cual se asentó la conformación del Estado nación. Es por ello que el mero hecho de manifestarse en la esfera pública, mostrar su existencia y reivindicar sus luchas ancestrales, transmitía en sí mismo un mensaje claro a las autoridades.

La estrategia consistió entonces en desarrollar foros de discusión, parlamentos y seminarios sobre el genocidio de los pueblos originarios, los derechos de los pueblos indígenas y el abordaje de las prácticas contemporáneas de opresión estatal. Muchas de estas acciones están focalizadas principalmente en el auto reconocimiento y el empoderamiento de las propias capacidades de las comunidades. En palabras de una de sus integrantes (Ailén), se trata de "usar todas las herramientas que tenemos para difundir, para hacer esta revolución cultural. Que se abra el debate, que empecemos a pisar fuerte de a poquito" (Polischuk, 2018).

La referente del Movimiento y principal foco de la persecución judicial y mediática, es Moira Millán, inan lonko de la comunidad Pillan Mahuiza (en la localidad de Corcovado, a $100 \mathrm{~km}$. de Esquel). Desde sus inicios, el Movimiento lleva como una de sus principales consignas la absolución de la weichafe mapuche-tehuelche, instalando en la agenda el lema "Reclamar Justicia No Es Delito".

La referente del Movimiento identifica las acciones de solidaridad con la comunidad mapuche-tehuelche Vuelta del Río (a 120 km de El Bolsón) como el germen de su persecución. Esta comunidad, que linda con la Pu Lof en Resistencia (Cushamen) donde fue visto por última vez con vida Santiago Maldonado, sufrió el incendio intencional de la casa de uno de sus miembros, quien participara de la toma pacífica del Juzgado Federal de Esquel para solicitar la renuncia del juez Otranto, a cargo de la causa de desaparición de Maldonado. En la toma del juzgado también participó Moira Millán, en repudio de éste y otros actos de violencia, como allanamientos y amedrentamiento a las familias de la comunidad, por supuestos vínculos con la desaparición de Santiago. Moira, además, fue la encargada de realizar el palpado de armas a los oficiales que realizarían allanamientos en la comunidad, ya que habían acordado ingresar sin armas. A partir de este momento, comenzó su hostigamiento, que fue in crescendo hasta convertirse actualmente en la única procesada por la toma del juzgado, acusada de coacción agravada, a pesar de haber sido absuelta por otro magistrado el 19 de septiembre de 2018. 
Con el objetivo de visibilización como meta, volcaron su estrategia hacia las redes sociales y plataformas virtuales como sus medios de difusión, tomando a Facebook como su base de comunicación y denuncia. Su exclusión de facto de los medios de comunicación hegemónicos obligó al Movimiento a optar por medios alternativos. Los elementos audiovisuales de su página oficial -videos, imágenes e infografías - conforman el corpus que será analizado a continuación, en función de las variables definidas previamente. Cabe destacar que la distinción de las variables es meramente analítica, en tanto el carácter de la lucha feminista, antiextractivista y plurinacional, se comprenden en su mutua interdependencia, configurando asimismo modos diversos de relacionamiento con los Estados. La decisión de trabajar con los documentos elaborados por el propio Movimiento, expresa la intención de dotar de voz a las comunidades, reconociéndolos como sujetos políticos con capacidad de expresar, en primera persona, sus demandas y propuestas. El corpus analizado incluye una selección de 24 imágenes, entre las que se distinguen invitaciones a charlas y jornadas, por un lado, y comunicaciones oficiales de carácter informativo o de denuncia, por el otro, que en algunos casos podrían aunarse bajo el calificativo de panfleto; así como 3 videos elaborados por el propio Movimiento, que adoptan un formato cercano al documental, por su capacidad narrativa de una realidad experimentada por los propios interlocutores.

\section{El rol de la mujer como líder}

La construcción de liderazgos femeninos dentro del Movimiento sigue dos grandes vías. La primera se liga con la figura de Moira Millán como representante de la lucha mapuche. Asimismo, en su presentación como weichafe -guerrera- subyace la idea de la heroína colectiva. La guerrera no es sólo la cara visible de un Movimiento plurinacional que es conducido por mujeres, sino que las imágenes y videos constituyen un explícito llamamiento a la acción, a embanderarse con la causa del grupo, para lograr una liberación que sólo es asequible a través del esfuerzo colectivo. La figura de Moira actúa como cohesionadora de estas luchas, pero es explícito el carácter colectivo, que halla sus raíces, asimismo, en la filosofía del Buen Vivir y en la perspectiva comunitaria propia de los pueblos indígenas. En las imágenes seleccionadas para este eje, se observa la figura de la representante del Movimiento mirando hacia el frente con la mano en alto, el puño cerrado y un fondo de paisaje natural, que expresa el carácter situado de la lucha, desde y por el cuerpo-territorio. Esta imagen se repite en varias de las invitaciones a charlas y comunicados oficiales, en blanco y negro y a color, particularmente desde el procesamiento de Moira, pidiendo su absolución. En todos los casos, es acompañado de los hashtags "Reclamar Justicia No Es Delito", "La Solidaridad No Es Delito", "La Lucha Por La Tierra No Es Un Crimen", "Libertad a Las Presas Por Luchar" (Concentración para pedir la absolución de Moira Millán, 21/02/2019).

Otra imagen que se repite es la de un grupo de mujeres, tomada desde abajo, entre las que se incluye Moira, todas con las manos en alto y el puño cerrado en señal de lucha. Particularmente esta imagen es utilizada para invitaciones a charlas o jornadas de discusión sobre 
el carácter feminista y plurinacional del Movimiento, donde la dignidad aparece como la idea fuerza que motoriza la lucha (Charla Abierta, Dignidad y rebelión desde la Mapu, Plurinacionalidad de los Territorios, 16/01/2019). Otra de las imágenes que suelen utilizarse para jornadas de discusión muestra a un grupo pequeño de mujeres, entre las que también se incluye Moira, sonriendo y conversando, en el propio territorio de la comunidad, sin mirar a la cámara (es el caso de la Jornada Plurinacional de Mujeres, 24/01/2019). Una última imagen que se repite es la de un grupo importante de mujeres indígenas movilizándose en su territorio, portando banderas y afiches en los que se llega a leer "Nos queremos plurinacional" (es el caso de la invitación al mismo encuentro). Interesa destacar que estas jornadas, que se realizaron durante el mes de enero de 2019, constituyeron un espacio de encuentro de mujeres mapuches e indígenas de otros pueblos, para discutir temáticas que las atraviesan a todas, desde la violencia de género, los abusos que sufren desde los aparatos punitivos enraizados por su carácter de mujeres e indígenas y cómo se posicionan las mujeres frente a los derechos.

La solidaridad es otro de los pilares sobre los que se asienta la lucha feminista -lo que en otros espacios ha adquirido el nombre de sororidad-. Esto puede observarse en el pedido de absolución de Moira Millán, reiterado el 30 de enero de 2019, en el que se denuncia que "nuestra hermana está siendo acusada por la justicia racista, que defiende los intereses de aquellos que quieren destruir la vida y junto con ello la espiritualidad de los pueblos preexistentes" (Llamado a la solidaridad de los pueblos para exigir la absolución de la weichafe Moira Millán, 30/01/2019). Este aspecto se comprenderá mejor a la luz de los análisis vertidos en el último eje, respecto a la relación con los Estados.

En otro comunicado, fechado el 26 de enero de 2019, se efectúa un llamamiento a la solidaridad y se denuncia la situación de empobrecimiento, feminicidios y contaminación que sufren las mujeres indígenas de Canadá, dotando al Movimiento de un carácter transnacional. En este documento se propone la creación de la Red de Mujeres Indígenas contra la Violencia de Género, para establecer un espacio en el que se visibilicen y se denuncien situaciones de violencia hacia la mujer, acompañándolas "en su reparación como mujeres desde su cosmovisión ancestral" (Denuncia de violencia de género hacia mujeres indígenas). Un último elemento a analizar en este eje está ligado a la lucha contra la violencia no sólo patriarcal, sino también racista. Un panfleto que denuncia las violencias racistas, lanzado el 25 de noviembre, Día Internacional de la lucha contra la violencia hacia las mujeres y disidencias, muestra las manos de lo que -se connota- son dos mujeres, tomándose en señal de acuerdo, una de las cuales porta el pañuelo verde característico de la campaña por el Aborto Legal, Seguro y Gratuito, mientras que la otra es de piel más oscura (Basta de Violencias Racistas).

El colectivo se sumó a la Marcha Internacional de Mujeres del 8 de marzo (8M), en la columna "Negras, indígenas, mujeres racializadas y disidencias", que promovía la consigna "Sembraron racismo, cosecharon la rebelión de las flores". En el panfleto que indica la participación del Movimiento en la movilización, se añade que es un "Paro Plurinacional Internacional de Mujeres lesbianas, travestis, trans y no binaries" (8/03/2019), se muestran un grupo importante de mujeres -entre las que se incluye Moira a la vanguardia de la movilización- con los brazos en alto y sus puños cerrados, en señal de grito. Una imagen similar se observó meses antes, en diciembre de 2018, cuando el MMIBV emitió un comunicado 
de repudio a los jueces que decidieron la absolución de los femicidas de Lucía Pérez. Allí se establece la siguiente consigna: "Si nuestros cuerpos no cuentan, produzcan sin nosotras" (Repudio a los jueces que absolvieron a los femicidas de Lucía Pérez, 5/12/2018).

En un video elaborado por el Movimiento previo al 8M, ya establecida la necesidad de un "Paro Plurinacional Internacional de Mujeres lesbianas, travestis, trans y no binaries", se proyectan testimonios de distintas mujeres -entre las que se incluye Moira- expresando los motivos de su participación en el paro:

Paramos para denunciar el sistema judicial colonial, racista, patriarcal y capitalista, por la libre determinación de nuestros pueblos, por la libre determinación de nuestros territorios, contra los feminicidios indígenas y contra el racismo, contra la trata y la prostitución infantil, la transfobia y los travesticidios. Paramos por la plurinacionalidad de todas las luchas territoriales.

Mientras se muestra la imagen de un grupo de mujeres movilizándose en el territorio, con elementos característicos de la identidad mapuche combinados con pañuelos verdes de la campaña por el Aborto Legal, Seguro y Gratuito, una voz en off resume de manera contundente el rol de la mujer en este Movimiento: "Somos las nietas de todas las indias que nunca pudieron matar". Visibilizar la lucha y visibilizar-se, desde los cuerpos territorios, en un reclamo que las une desde su triple identidad: de género, étnica y de clase.

\section{La reivindicación de la Plurinacionalidad}

En estrecha vinculación con la reivindicación de género, se encuentra la demanda de reconocimiento de las diversas naciones indígenas. Si bien algunas de estas premisas fueron indicadas anteriormente, con motivo de la participación del colectivo en el $8 \mathrm{M}$, interesa profundizar el modo en que el Movimiento se define en términos de Plurinacionalidad. Un elemento que acompaña todas las comunicaciones del Movimiento es el hashtag "Nos Queremos Plurinacional", junto con un logotipo creado por el MMIBV para promover la plurinacionalidad del Encuentro Nacional de Mujeres de Argentina. Al tratarse de la confluencia de 36 naciones originarias, la plurinacionalidad es un dato que las constituye desde sus inicios. En un comunicado emitido el 15 de octubre de 2018 desde Trelew y bajo el título "El grito que no pudieron silenciar", se establece la institucionalización de este rasgo al interior del colectivo:

Sepan que ha nacido una nueva fuerza expresada en este movimiento de mujeres que construye su camino desde el pensamiento ancestral de nuestras naciones originarias, heredando el mandato de nuestros antepasados de resguardar la vida. Esto nos lleva a ser autónomas, autogestivas, sin partido, son religiones, somos mujeres indígenas autoconvocadas para construir en Buen Vivir como Derecho. Venimos haciendo un largo camino de muchos años en la lucha por la visibilidad y reconocimiento de nuestras realidades y problemáticas (El grito que no pudieron silenciar, Nos queremos Plurinacional, 15/10/2018). 
El 4 de marzo de 2019, otro comunicado titulado “De dónde nació la Campaña \#NosQueremosPlurinacional", se ofrecen algunas aclaraciones respecto a lo que públicamente apareció como un simple pedido de cambio de nombre del Encuentro Nacional de Mujeres a Encuentro Plurinacional de Mujeres, Lesbianas, Travestis y Trans. Allí se denuncia que no se trata meramente de un cambio de nombre, sino que implica convertir al encuentro en un espacio realmente plurinacional y no sólo en términos retóricos. "En este Estado genocida, racista, patriarcal y misógino, resulta muy difícil emplazar nuestros derechos como naciones indígenas". A partir de estas premisas, se efectúa un llamamiento a la unidad: "Nosotras podemos cambiar el mundo, parar el sistema y construir en unidad, los sueños de una nueva humanidad, en el que la libre determinación de nuestros cuerpos, territorios y pueblos sean realidad y no una utopía inalcanzable" (De dónde nació la Campaña \#NosQueremosPlurinacional, 4/03/2019).

En un panfleto mencionado en el eje anterior (Denuncia de violencia de género hacia mujeres indígenas, 26/01/2019), se hace referencia a esta transformación en el carácter del Movimiento, especificando que la plurinacionalidad implica un cambio de estructura, no sólo de forma, un cambio que amplifique "nuestras formas de habitar el territorio y nuestros cuerpos-territorio".

Las tensiones entre el Encuentro Nacional de Mujeres y el MMIBV que propugnaba la incorporación de la plurinacionalidad, se evidenciaron en dos comunicados del 11 de octubre de 2018. El primero, más extenso, titulado " $33^{\circ}$ ENM Chubut, Prohíbe la Consulta Plurinacional”, señala la ironía de estas exclusiones en el día de conmemoración de la resistencia de los pueblos originarios de todo el continente. El intento de acallar las voces y las propuestas del Movimiento, la folclorización de las comunidades "negando nuestra capacidad de autodeterminarnos en el pensamiento, en la acción, y en la propuesta", así como la apropiación, por parte de la comisión organizadora, de una ceremonia propuesta por las integrantes del MMIBV, fueron los principales núcleos de las disputas, que expresan la persistencia de estructuras patriarcales, machistas y/o nacionalistas incluso en estos espacios. Otro breve comunicado emitido el mismo 11 de octubre de 2018, anunció que no participarían del acto inaugural del $33^{\circ}$ Encuentro Nacional de Mujeres Trelew 2018, pero sí recibirían a las congregaciones de mujeres "honrando nuestro carácter de anfitrionas por ser mujeres ancestrales en este territorio (...) Puelwillimapu, territorio mapuche-tehuelche", acompañándolas para "compartir nuestros sueños de equidad y liberación para todxs" (Taller 42 Somos Todxs, 11/10/2018).

En torno a la construcción de la plurinacionalidad, bajo la consigna "Por la libre determinación de los cuerpos", se incluye también un comunicado de adhesión a la vigilia por el tratamiento de la Ley de Interrupción Voluntaria del Embarazo, desde las identidades afro e indígenas "hermanadas en la lucha", correspondiente a la vigilia realizada el 8 de agosto de 2018, cuando el proyecto de Ley comenzó a ser tratado en el Senado nacional -y rechazado al día siguiente-.

Un último elemento que constituye este eje de indagación constituye una crítica al estatus de objeto de estudio que se les ha impuesto desde una lectura académica occidental. En un panfleto titulado "Ya no más objetos de estudio", el MMIBV, el Grupo Matambas y el Espacio Afro Indígena, Mujeres Racializadas y Disidencias se repone la necesidad de conformar 
un Encuentro de Mujeres "que no niegue a las más de 36 Naciones Indígenas", en miras al $34^{\circ}$ Encuentro Plurinacional de Mujeres lesbianas, travestis, bisexuales y transexuales.

\section{El carácter de la lucha y su vínculo con los Estados}

En este apartado se abordan tres sub-ejes: la relación del Movimiento con los Estados provincial y nacional; la defensa de la tierra como una respuesta al avasallamiento de las empresas extractivas; y el Buen Vivir como una propuesta de desarrollo alternativo al modelo hegemónico centrado en la explotación intensiva de la naturaleza.

Es importante retomar aquí a Acosta (2012) cuando caracteriza a los procesos posneoliberales como más Estado-intervencionistas, pero no poscapitalistas. La diferencia que establece es sustancial para el propósito de este artículo, en tanto resulta innegable la mayor intervención de los Estados en el establecimiento de políticas sociales tendientes a mejorar los índices de acceso a la salud y la educación, impedir la reproducción intergeneracional de la pobreza y otorgar mejores condiciones de vida a la tercera edad. En términos fiscales, sostendrá Lander (2014), el Estado recuperó espacios imprescindibles de gestión. Sin embargo, esto no ha incidido en la superación de la situación de dependencia económica o del modelo sustentado en la exportación de commodities.

Como se planteara en los primeros apartados, esto ha influido en la generación de conflictos con las comunidades indígenas, manifestándose en prácticas de criminalización y judicialización de sus formas de protesta. Los asesinatos de Santiago Maldonado y Rafael Nahuel, visibilizan la máxima expresión de este proceso. Los comunicados de denuncia y panfletos analizados aquí, refieren a pedidos de justicia por el hostigamiento cotidiano del que son víctimas, visibilizado a partir de la desaparición seguida de muerte de Santiago Maldonado. En el caso de los primeros recursos analizados, se vinculan con el comunicado acerca del intento de detención de Moira Millán el 8 de julio de 2018, donde comienza a instalarse la campaña "Reclamar Justicia No es Delito" y los sucesivos pedidos de absolución. Una de las primeras imágenes que se viralizó para acompañar a la weichafe la mostraba en un primer plano con el puño cerrado en alto y en señal de grito, con la bandera mapuche de fondo. Esta imagen fue difundida para acompañar su regreso desde Colombia al aeropuerto de Ezeiza el 8 de julio, ante el temor de que fuera detenida.

A partir de entonces se inició una campaña solicitando adhesiones para pedir su absolución definitiva. Esta campaña recibió más de ochenta videos de diferentes personas del ámbito de la actuación -Juan Palomino, Malena Pichot, Susana Varela-, la defensa de los derechos humanos -Nora Cortiñas, de la organización Madres de Plaza de Mayo Línea Fundadora-, la investigación y la docencia, el periodismo y el ámbito cultural, así como de otros pueblos indígenas de Argentina y Latinoamérica, trabajadores y agrupaciones de Chile, Barcelona, Honduras y el País Vasco, entre otros. En cada uno de estos videos, de entre 15 y 40 segundos de duración, la persona o grupo que manifestaba su adhesión al pedido de absolución, reiteraba el lema de la campaña "Reclamar Justicia No es Delito". A estas acciones, se sumaron nuevas jornadas de concientización sobre la persecución y judicialización de los pueblos indígenas, realizadas en los territorios recuperados de la 
Lof Pillán Mahuiza. La invitación a las jornadas se compuso de una imagen de fondo que muestra un paisaje natural, el propio territorio de la comunidad, y una movilización de mujeres con carteles y afiches en los que se puede leer las denuncias de criminalización y los pedidos de justicia (Jornadas contra la persecución y judicialización de los pueblos, 17/02/2019). Estas jornadas se desarrollaron durante el 18, 19 y 20 de febrero de 2019, en el marco de la vigilia convocada para acompañar a Moira Millán, quien debía presentarse a declarar el 21 de febrero.

Otro de los recursos empleados para el análisis incluye una convocatoria a movilizarse para reclamar justicia a 14 meses del asesinato de Rafael Nahuel, donde tres hashtags son utilizados: "Que tu silencio no sea cómplice", "Fue el Estado", "Fue Prefectura". Se observa una imagen del rostro de Rafael Nahuel, rodeado de un círculo con los colores característicos del Movimiento. Resulta interesante el modo en que se expresa el sitio de reunión -en el Monumento "al genocida Julio A. Roca", CABA-, que se complementa con la leyenda: "14 meses de una Justicia Occidental, Racista y Colonial que no condena a los autores materiales e intelectuales (...), del silencio cómplice de los medios de comunicación, del aparato jurídico, de los partidos políticos, de la sociedad" (Justicia por Rafael Nahuel, 25/01/2019).

Un comunicado similar se emitió el 29 de agosto de 2018 en apoyo al lonko de la Pu Lof en Resistencia de Cushamen, Facundo Jones Huala -uno de los principales testigos del asesinato de Rafael Nahuel-, quien fue detenido, extraditado a Chile y condenado a nueve años de prisión por su supuesta participación en el incendio de una finca en 2013. En este comunicado, desmienten noticias falsas difundidas por el periódico Clarín, que en distintas ocasiones han contribuido a "generar una campaña de difamación contra Moira Millán”, al mismo tiempo que han alimentado la hipótesis gubernamental que los señala como organización terrorista. Se denuncia, en este mismo documento, el nexo entre las noticias difundidas por este multimedio y el Informe R.A.M. realizado entre el Ministerio de Seguridad nacional y los gobiernos de Río Negro, Chubut y Neuquén "que buscan construir 'enemigos internos' para legitimar sus siniestras represiones a la Nación Mapuche y a todo militante social que luche por el Buen Vivir como Derecho" (Comunicado de apoyo a Facundo Jones Huala, 29/08/2018).

Asimismo, el 11 de noviembre de 2018, el Movimiento emitió un comunicado de repudio por el asesinato del weichafe Camilo Catrillanca en la IX Región de Chile -La Araucanía-, por un sargento de las fuerzas especiales de Carabineros. En los casos en que el contenido del comunicado es más relevante que una imagen, suele optarse por un recurso compositivo simple -fondo blanco con letras negras-, para visibilizar el poder enunciativo del mensaje que se transmite. En este comunicado se lee:

Es fundamental el despertar de la unidad de los pueblos para repudiar el accionar represivo y genocida de los estados chileno y argentino, contra el pueblo Mapuche. Aquí hay una guerra de baja intensidad contra una nación, la nación mapuche. (...) No vamos a admitir que ser joven mapuche signifique un riesgo letal para nuestras hijas, para nuestros hijos. El mundo entero debe repudiar la mano criminal que instrumentan estas armas, sobre los cuerpos territorio de nuestros hermanos y hermanas a lo largo de la Wallmapu (Repudio por el asesinato de Camilo Catrillanca, 11/11/2018). 
Los pedidos de solidaridad, sin embargo, no se ciernen sólo sobre los colectivos indígenas, sino que abarcan a miembros de la clase obrera argentina que son criminalizados en el marco de protestas sociales, como es el caso del comunicado de solidaridad con los trabajadores despedidos del Astillero Río Santiago, donde se lee "Si tocan a uno tocan a Tod@s", en letras negras con fondo blanco (20/01/2019). Asimismo, en un video viralizado en el marco de la crisis política venezolana que se desatara en enero de 2019, se observa a Moira acompañada de otro miembro de la comunidad, con la bandera mapuche de fondo, en la que expresan su solidaridad con el pueblo frente a lo que el Movimiento define como "la configuración de un escenario belicista en Indoamérica", por parte de Estados Unidos (Solidaridad con el pueblo venezolano, enero 2019).

Finalmente, se ofrece una lectura sobre el Buen Vivir como un modelo de desarrollo alternativo posible. El Buen Vivir es una filosofía vinculada originariamente a la cosmovisión andina. Según Svampa (2013), si bien es posible hallar lazos que la ligan a la "memoria larga, la cosmovisión relacional y comunitaria”, se trata de una construcción históricosocial que emerge después de los 2000 (p. 381). La autora señala que hasta el 2010 el Buen Vivir constituía una crítica radical al modelo de desarrollo vigente y una defensa a la Pachamama. Tanto Bolivia como Ecuador, que en el contexto regional implementaron un modelo de Socialismo del Siglo XXI , introdujeron elementos de la filosofía del Buen Vivir en sus constituciones. Sin embargo, hacia 2010-2011, producto de la existencia, incluso en estos países, de conflictos entre las empresas extractivas y las comunidades campesinas e indígenas perjudicadas por estas actividades, comenzó a romperse este consenso.

En un video subido a la plataforma de Facebook del Movimiento el 5 de septiembre de 2018, se observa a Moira en una entrevista en la que vincula los conflictos de la provincia de Chubut con el modelo económico gestado al calor del "consenso de los commodities" (Svampa, 2012), al evidenciar que dicha región es geopolíticamente estratégica, en función de los intereses de las corporaciones extractivistas". Luego se lee, en fondo negro con letras blancas: "Hay en Argentina más de 20 procesados mapuches vinculados de alguna manera al conflicto Benetton".

Este último recurso analizado es fundante del Movimiento, ya que en él se expresa cabalmente tanto el carácter de la lucha del MMIBV, como sus relaciones con los Estados y las estrategias de resistencia que despliegan. Al inicio del video se la ve a Moira hablando a cámara, expresando que: "el pueblo Mapuche no lucha por la propiedad de la tierra sino por un modo de vida en la tierra, un modo de vida que restablece justamente la armonía”. A continuación, se la ve caminando por las tierras de la comunidad Pillán Mahuiza, recuperadas a Benetton, y mientras la cámara la sigue, se lee: "Desde sus 21 años recorre el país conociendo las comunidades y sus realidades, en la defensa de los territorios y el medio ambiente". También se resume cómo llegó esta "guardiana de la tierra" a ser la única procesada por la ocupación pacífica del Juzgado Federal de Esquel el 20 de septiembre de 2017, en un acto de solidaridad con la comunidad Vuelta del Río. Este material resume, tanto en su contenido textual como en la elección de los recursos narrativos, la triple lucha del Movimiento por la libre determinación de los cuerpos-territorios; el fin de las discriminaciones y exclusiones sustentadas en el género, la raza o la orientación sexual; y el desarrollo de un modo de subsistencia en armonía con la naturaleza. 


\section{Conclusiones}

Los ejes analizados en este artículo expresan, de manera condensada, el leit motiv del Movimiento de Mujeres Indígenas por el Buen Vivir y, al mismo tiempo, exploran las estrategias alternativas de visibilización y comunicación con la ciudadanía que debieron desarrollar, frente al silenciamiento mediático y político.

Los materiales de difusión funcionan, en algunos casos, como hitos en la constitución del carácter feminista, plurinacional y antiextractivista del Movimiento, pero en otras ocasiones son respuestas frente a los diversos escenarios que la propia realidad local, nacional e internacional le impone. En efecto, como se visibilizó con motivo del Encuentro Nacional de Mujeres, la sola referencia a la lucha feminista no necesariamente implica la unificación detrás de un mismo significante. El Movimiento tensiona las fronteras cognoscibles y los repertorios de acción de otras expresiones que ya representan una ruptura con el orden establecido. Trasciende, asimismo, los usos normativizados de una plataforma virtual que es empleada hegemónicamente para entretenimiento, convirtiéndola en una herramienta de visibilización, demanda y lucha.

El rol de las mujeres dentro del Movimiento adopta el formato del liderazgo comunitario: la heroína aquí es necesariamente colectiva. La figura de Moira Millán como guardiana de la tierra funciona como elemento cohesionador de estas luchas, pero desde una perspectiva comunitaria y decolonial que exige eliminar las lógicas de jerarquización de los movimientos sociales occidentales. Se lucha desde los cuerpos-territorios, ya que en ellos se inscriben siglos de opresión, pero también desde ellos se construye una alternativa.

La demanda de Plurinacionalidad disputa el sentido que esta noción ha adquirido en torno a los procesos de institucionalización de la filosofía del Buen Vivir a nivel constitucional en Bolivia y Ecuador. La vigencia de esta demanda expresa la persistencia de estructuras racistas y nacionalistas que han negado el genocidio originario y afrodescendiente y que adoptan parcialmente algunos elementos de esta filosofía, erosionando su potencial de crítica.

Las denuncias de criminalización, persecución y hostigamiento que sufren las comunidades, tensionan, finalmente, los discursos gubernamentales que intentar construir una imagen de violencia irracional en torno a estas demandas. Reintroducen la historia en estas construcciones político-mediáticas y demuestran, una vez más, su posicionamiento como sujetos políticos con capacidad de expresarse por sus propios medios, sin necesidad de ser "hablados" por otros.

\section{Notas}

1. Este conjunto de programas, como la Asignación Universal por Hijo para Protección Social en Argentina, Bolsa Familia en Brasil o el Plan Nacional de Emergencia Social de Uruguay, se implementaron en toda la región desde inicios de este siglo con un paradigma superador del asistencialismo de la década de 1990. La condicionalidad se instaura a partir de la obligación de la madre, padre o tutor/a de garantizar al niño/niña el acceso al sistema de salud y educación (Vilas, 2016). 
2. Algunos artículos periodísticos difundidos en los medios hegemónicos demuestran esta intencionalidad. Por citar algunos ejemplos: "Patricia Bullrich habla en el Senado: 'Los mapuches son un grupo de extrema violencia". (16 de agosto de 2017). La Izquierda Diario. Disponible en: http://www.laizquierdadiario.com/Patricia-Bullrich-habla-en-elSenado-Los-mapuches-son-un-grupo-de-extrema-violencia / "Garavano y Bullrich, sobre los mapuches: 'Estas comunidades RAM no respetan la ley"'. (27 de noviembre de 2017). Perfil. Disponible en: https://www.perfil.com/noticias/politica/garavano-y-bullrich-realizan-una-conferencia-de-prensa.phtml / "Patricia Bullrich tras la represión a los mapuches: 'Se terminó la impunidad de la que gozaron tantos años (19 de julio de 2018). Minuto 1. Disponible en: https://www.minutouno.com/notas/3081163-patricia-bullrichla-represion-mapuches-se-termino-la-impunidad-la-que-gozaron-tantos-anos / "Macri sobre las tensiones con los mapuches por Villa Mascardi: 'Se hace difícil encontrar un canal de diálogo'. (20 de julio de 2018). Infobae. Disponible en: https://www.infobae.com/ politica/2018/07/20/en-medio-de-las-tensiones-con-los-mapuches-por-villa-mascardiel-presidente-macri-viaja-a-bariloche/

3. Según Lander (2014), para 2010, la soja llegó a abarcar el 59\% de la tierra cultivada en Argentina.

4. Se denomina "techo de cristal" a las diversas formas de discriminación laboral de las mujeres en puestos directivos. Desde la perspectiva de género, se observa que hay una discriminación, invisible pero real, que conduce a optar por hombres antes que mujeres para ocupar puestos de toma de decisiones en las estructuras corporativas, a pesar de contar con igual o mayor formación académica o los mismos antecedentes laborales. Esto impacta, como es evidente, en los salarios percibidos, que distan de ser equitativos (Morrison, 1992; Holloway, 2002; Barrancos, 2012).

5. En Argentina, entre enero y marzo de 2019 fueron cometidos 54 feminicidios. En 2018, 241 mujeres fueron asesinadas en contextos de violencia de género, según el Informe de Investigación de Femicidios en Argentina 2018, realizado por el Observatorio de Femicidios Adriana Marisel Zambrano, Asociación Civil La Casa del Encuentro.

6. En mapudungun, segunda autoridad.

7. En mapudungun, guerrera.

8. La desaparición de Santiago Maldonado el 1 de agosto de 2017, marcó el inicio de una serie de acusaciones y persecuciones del gobierno nacional hacia las comunidades indígenas de la Pu Lof en Resistencia Cushamen, donde fue visto con vida por última vez, pero también hacia otras comunidades mapuches de la zona. La desaparición de Santiago se dio en el contexto de un operativo encabezado por Gendarmería Nacional en la Pu Lof. Tras 78 días de búsqueda, el 17 de octubre su cuerpo fue encontrado en el río Chubut. Además del intento mediático y político de estigmatizarlo, tanto la Ministra de Seguridad como otros funcionarios del gobierno nacional realizaron ingentes esfuerzos por responsabilizar a los mapuches por su deceso, en una primera instancia, para luego dar por cerrado el caso ofreciendo una interpretación maniquea de los resultados de la autopsia y afirmar que se trató de una muerte accidental. Para una cronología completa del caso, se sugiere ver la página creada por familiares de Santiago Maldonado: http://www.santiagomaldonado.com/ 
9. La comunidad se encuentra ubicada en la Reserva Indígena Cushamen, que "cuenta con Personería Jurídica Nacional y Provincial desde 1997, y ocupa tierras en forma tradicional y ancestral desde finales del Siglo XIX, siendo una población de unas 30 familias preexistentes al Estado Nacional y Provincial, sobrevivientes a la mal llamada Conquista del Desierto" (Habeas Corpus preventivo presentado por Isidoro Silvio Huilinao, Presidente de la Comunidad Mapuche-Tehuelche Vuelta del Río, 18/09/2017).

10. Para la interpretación de las imágenes e infografías, se hizo foco en los niveles narrativo y compositivo, soslayando los aspectos técnicos.

11. El femicidio de Lucía Pérez, una joven marplatense de 16 años, quedó impune tras la decisión del Tribunal Oral en lo Criminal de la ciudad de Mar del Plata de absolver a los tres acusados por abuso sexual y femicidio en un contexto de violencia extrema, ocurrido en 2016.

12. Grupo Matambas, Negras, indígenas, racializadas y disidencias.

13. Rafael Nahuel, de 22 años, fue asesinado por un cabo de la Prefectura Naval Argentina, en el marco de un operativo de desalojo de la comunidad Lafken Winkul Mapu, situada en las zonas aledañas al lago Mascardi, en Río Negro, entre el 23 y el 25 de noviembre de 2017. 14. Socialismo del Siglo XXI fue el nombre que adquirieron los procesos liderados por Hugo Chávez en Venezuela (1999-2013), Rafael Correa en Ecuador (2007-2017) y Evo Morales en Bolivia (2006-). Más allá de los antecedentes académicos del término, comenzó a emplearse para caracterizar a estos gobiernos a partir de 2005, luego de que el ex presidente venezolano lo utilizara en un discurso brindado en el marco del V Foro Social Mundial.

15. Luciano Benetton es uno de los principales propietarios de tierras de la Patagonia argentina. Solamente entre 1991 y 1997 acumuló 900.000 hectáreas. También figuran en la lista de propietarios Ted Turner (creador de la CNN), los Suchard, George Soros, Sylvester Stallone y Ward Lay (hijo de uno de los fundadores de Pepsico) (Ferri, 19 de agosto de 2017).

\section{Listas de Referencias Bibliográficas}

Acosta, A. (2012). El retorno del Estado. Primeros pasos postneoliberales, más no postcapitalistas. Contextualizaciones latinoamericanas, 4 (7).

Arceo, E. (2009). América Latina. Los límites de un crecimiento exportador sin cambio estructural. En Arceo, E. y Basualdo, E. (comps.) Los condicionantes de la crisis en América Latina. Inserción internacional y modalidades de acumulación. Buenos Aires: CLACSO.

Espinosa et al (2014). Tejiendo de otro modo: Feminismo, epistemología y apuestas descoloniales en Abya Yala. Editorial Universidad del Cauca. En Varea, S. y Zaragocin, S. (comp.). (2017). Feminismo y Buen Vivir. Utopías decoloniales. Cuenca: Pydlos Ediciones.

Ferri, C. (19 de agosto de 2017). La historia del Imperio Benetton, el dueño de la Patagonia. La Izquierda Diario. Disponible en: http://www.laizquierdadiario.com/La-historia-delimperio-Benetton-el-dueno-de-la-Patagonia

Harvey, D. (2005). El nuevo imperialismo: acumulación por desposesión. Socialist Register. Buenos Aires: CLACSO. 
Hernández Castillo, A. (2014). Confrontando la Utopía Desarrollista: El Buen Vivir y la Comunalidad en las luchas de las Mujeres Indígenas. En Varea, S. y Zaragocin, S. (comp.). (2017). Feminismo y Buen Vivir. Utopías decoloniales. Cuenca: Pydlos Ediciones.

Lander, E. (2014). El Neoextractivismo como modelo de desarrollo en América Latina y sus contradicciones. Berlín: Heinrich Böll Stiftung.

Lenton, D.; Delrio, W.; Pérez, P.; Papazian, A.; Nagy, M. y Musante, M. (2011). Huellas de un genocidio silenciado: los indígenas en Argentina. Revista Social Latinoamericana, 1 (6). UNAM-FES Aragon, México.

Lenton, D. (2018). De genocidio en genocidio. Notas sobre el registro de la represión a la militancia indígena. Revista de Estudios sobre Genocidio, 13 (9).

Marx, K. ([1867]1998). El Capital. Crítica de la economía política. Buenos Aires: Siglo Veintiuno.

Mendoza, M. y Nikolajczuk, M. (2016). Desarrollo y modelos de acumulación en América Latina en el siglo XXI. Continuidades y rupturas en torno a los procesos de acumulación en Perú y Ecuador. Revista paraguaya de Sociología, 149, Centro Paraguayo de Estudios Sociológicos.

Papazian, A. (20 de diciembre de 2017). En Paterno, F. ¿Quépasa con los pueblos originarios? (entrevista), Ancap.

Polischuk, S. (julio 2018). Argentina: Lanzamiento del Movimiento de Mujeres indígenas por el Buen Vivir / Comunicado de solidaridad con Moira Millan. Resumen Latinoamericano. Disponible en: http://www.resumenlatinoamericano.org/2018/07/01/lanzamiento-delmovimiento-de-mujeres-indigenas-por-el-buen-vivir/

Prado, M. (1966). La guerra al malón. Buenos Aires: Eudeba.

Scandizo, H. y Álvarez Mullalli, M. (2018). Compañias europeas a la conquista de Vaca Muerta. Siete empresas en el horizonte no convencional de la Cuenca Neuquina. Patagonia Norte: Enlace por la Justicia Energética y Socioambiental (EJES), Oilwatch y Observatorio Petrolero Sur.

Se agrava el terrorismo de Estado. (Septiembre 2017). Radio Caput. Disponible en: https:// radiocaput.com/se-agrava-la-persecucion-a-los-mapuches-la-palabra-pesadilla-es-poco/

Svampa, M. (2016). Capítulo 2: Debates sobre el desarrollo. Debates latinoamericanos. Indianismo, desarrollo, dependencia y populismo. Buenos Aires: Edhasa. pp. 367-401.

Varea, S. y Zaragocin, S. (comp.). (2017). Feminismo y Buen Vivir. Utopías decoloniales. Cuenca: Pydlos Ediciones.

Vilas, C. (2016). Política social: ¿hacia un nuevo paradigma? Estado \& comunes, 1(1). Disponible en: http://cmvilas.com.ar/index.php/articulos/12-politicas-publicas/77-politicasocial-hacia-un-nuevo-paradigma

Abstract: On June 30, 2018, the Movement of Indigenous Women for the Good Living (MMIBV) made its first public appearance on the Argentine political scene. With the March of Original Women as antecedent (created in 2012), the plurinational organization manifested the need to make visible a complex network of struggles rooted in its triple exclusion: ethnic, gender and class. 
Gradually, and in the heat of the exacerbation of the conflicts between the national states and the original communities, the movement acquired an anti-extractive character, promoting the Good Living as a model of alternative development. The criminalization of social and territorial protest in particular, which in Argentina has radicalized during Mauricio Macri's administration (2015), as well as the judicial prosecution of Mapuche leaders in a strategy that exceeds national limits, demanded a change in the initial communication scheme of the Movement.

In this article we propose to analyze the MMIBV from its diffusion, audiovisual and infographic materials, in a temporal period that goes from its emergence in the middle of 2018 to March 2019. The communication and visibility strategy of the Movement is entirely digital, using the Facebook platform as the main axis of its link with the citizens. Their de facto exclusion from the hegemonic media and the slight -or none-public perception of the problem that these communities are going through -with the systematic silencing of local and national public officials- led to the use of alternative mechanisms of debate and denunciation.

This element is of particular interest, since it is not simply an election, but it reflects the ability to be recognized in the public sphere only through this medium. Likewise, the very nature of this platform permeates the content of the pieces, their capacity for replication, the modes of dissemination and discursive strategies.

That is why this article proposes to describe and explore the official and material dissemination material of the MMIBV, based on five lines of inquiry: 1. the role of women as a leader; 2. the vindication of their ethnic, gender and class identity; 3. the search for relations of horizontality -inter and intracommunity, with the population as a whole, between men and women-; 4. the conception of nature and its ancestral precepts in the development of an alternative development model; 5. the nature of the struggle and its link with the States -local, national and international-.

Keywords: Indigenous communities - antiextractivism - feminism - criminalization - ancestral territories - plurinationality - indigenous genocide - official communications - social networks - visibilization

Resumo: O 30 de junho de 2018, o Movimento de Mulheres Indígenas pelo Bom Viver (MMIBV) fez sua primeira aparição público no cenário político argentino. Com a Marcha de Mulheres Originarias como antecedente (criada em 2012), a organização plurinacional manifestou a necessidade de visibilizar uma complexa rede de lutas enraizadas em seu triplo exclusão: étnica, de gênero e de classe.

Gradualmente, e ao calor da exacerbação dos conflitos entre os estados nacionais e as comunidades originarias, o movimento adquiriu um caráter anti-extrativista, promovendo o Bom Viver como um modelo de desenvolvimento alternativo.

A criminalização do protesto social - e particularmente-territorial -, que em Argentina se radicalizou durante o mandato do presidente Mauricio Macri (2015-), bem como o processamento judicial de líderes mapuches em uma estratégia que excede os limites nacionais, exigiu uma mudança no esquema de comunicação inicial do Movimento. Neste artigo propõe-se analisar o MMIBV a partir de seus materiais de difusão, audiovisuais e 
infográficas, em um período temporário que abarca desde seu surgimento em meados de 2018 até março de 2019. A estratégia de comunicação e visualização do Movimento é integralmente digital, utilizando a plataforma de Facebook como eixo principal de seu vínculo com a cidadania.

Sua exclusão de facto dos meios de difusão hegemónicos e a escassa ou nula percepção pública do problema que atravessam estas comunidades -ante o sistemático silenciamiento dos servidores públicos públicos locais e nacionais- implicou à utilização de mecanismos alternativos de debate e denúncia.

Este elemento resulta de particular interesse, em tanto não se trata simplesmente de uma eleição, sina que reflete a capacidade de ser reconhecidas na esfera pública através desta única via em massa. Assim mesmo, o próprio caráter desta plataforma permeia o conteúdo das peças, sua capacidade de replicação, as modalidades de difusão e as estratégias discursivas. É por isso que o presente artigo propõe descrever e explorar os comunicados oficiais e materiais de difusão do MMIBV, a partir de cinco linhas de pesquisa: 1. o papel da mulher como líder; a reivindicação de sua identidade étnica, de gênero e de classe; 3. a busca de relações de horizontalidad -inter e intracomunitaria, com a população em seu conjunto, entre homens e mulheres-; 4. a concepção da natureza e seus preceitos ancestrales no desenvolvimento de um modelo de desenvolvimento alternativo; 5. o caráter da luta e seu vínculo com os Estados -locais, nacionais e internacionais-.

Palavras chave: Comunidades originais - antiextrativismo - feminismo - criminalização - territórios ancestrais - plurinacionalidade - genocídio original - comunicados oficiais redes sociais - visibilidade

[Las traducciones de los abstracts fueron supervisadas por el autor de cada artículo] 